Illinois State University

ISU ReD: Research and eData

Theses and Dissertations

3-17-2016

\title{
The Effects Of Two Different Resistance Training Protocols With Similar Volume On Muscular Strength, Muscle Thickness, And Fat- Free Mass
}

Cory Worthey

Illinois State University, cdworth12@gmail.com

Follow this and additional works at: https://ir.library.illinoisstate.edu/etd

Part of the Kinesiology Commons, Medicine and Health Sciences Commons, and the Physiology Commons

\section{Recommended Citation}

Worthey, Cory, "The Effects Of Two Different Resistance Training Protocols With Similar Volume On Muscular Strength, Muscle Thickness, And Fat-Free Mass" (2016). Theses and Dissertations. 556.

https://ir.library.illinoisstate.edu/etd/556

This Thesis is brought to you for free and open access by ISU ReD: Research and eData. It has been accepted for inclusion in Theses and Dissertations by an authorized administrator of ISU ReD: Research and eData. For more information, please contact ISUReD@ilstu.edu. 


\title{
THE EFFECTS OF TWO DIFFERENT RESISTANCE TRAINING PROTOCOLS WITH SIMILAR VOLUME ON MUSCULAR STRENGTH, MUSCLE THICKNESS, AND FAT-FREE MASS
}

\author{
Cory D. Worthey
}

\section{Pages}

The manipulation of exercise volume, intensity, and order is associated with producing different musculoskeletal changes. These resistance training program variables affect mechanical tension and metabolic stress associated with resistance training, therefore affecting strength and hypertrophic outcomes. PURPOSE: The purpose of this study was to examine the effects of two different volume-equated total body exercise protocols over 9 weeks using compound exercises on muscular strength, muscle thickness, and fatfree mass. METHODS: Eight well-trained men were randomly assigned to a hypertrophy-style protocol (HG) performing 3 sets of 10 repetitions with 90 seconds rest between sets $(n=4)$ or a strength-style protocol $(\mathrm{SG})$ performing 7 sets of 3 repetitions with 3 minutes rest between sets $(n=4)$. All subjects underwent pre-, mid-, and posttesting in body composition analysis via air displacement plethysmography and muscle thickness ultrasound imaging of four different sites: forearm flexors (FF), forearm extensors (FE), rectus femoris (RF), and vastus lateralis (VL). Imaging was done at two separate areas of each muscle site: proximal and distal. One repetition maximum (1RM) testing for the barbell back squat and barbell bench press was also conducted. 
RESULTS: After 9 weeks, maximal back squat increased $16.1 \pm 9.2 \%$ for SG and $5.5 \pm$ $1.7 \%$ for $\mathrm{HG}$ with no significant differences observed in $\mathrm{SG}(\mathrm{ES}=0.84)$ compared to HG $(\mathrm{ES}=0.31)(p=0.70)$. For the bench press, an increase of $16.0 \pm 13.1 \%$ was observed in $\mathrm{SG}$ and $6.9 \pm 2.7 \%$ for $\mathrm{HG}$ with no significant differences observed in $\mathrm{SG}(\mathrm{ES}=0.72)$ compared to $\mathrm{HG}(\mathrm{ES}=0.36)(p=0.17)$. Results for muscle thickness measurements are as follows: proximal $\mathrm{FF}=2.87$ vs. $-6.35 \%$, distal $\mathrm{FF}=-0.55$ vs. $-3.72 \%$, proximal $\mathrm{FE}=$ 7.99 vs. $-2.49 \%$, distal $\mathrm{FE}=19.42$ vs. $-2.05 \%$, proximal $\mathrm{RF}=3.89$ vs. $-0.04 \%$, distal $\mathrm{RF}$ $=4.64$ vs. $-4.85 \%$, proximal VL $=-2.81$ vs. $8.84 \%$, distal $\mathrm{VL}=10.30$ vs. $5.34 \%$. With the exception of the proximal forearm flexors, there were no significant differences in muscle thickness measurements between groups. There were no significant differences in changes to fat-free mass between groups or over the course of the intervention. CONCLUSIONS: When training volume is roughly volume-equated, a total-body exercise protocol produces changes in maximal strength, most measures of muscle thickness, and fat-free mass that are not significantly different between strength- and hypertrophy-style resistance training routines.

KEYWORDS: Hypertrophy, Intensity, Muscle, Resistance Training, Strength, Volume 
THE EFFECTS OF TWO DIFFERENT RESISTANCE TRAINING PROTOCOLS WITH SIMILAR VOLUME ON MUSCULAR STRENGTH, MUSCLE THICKNESS, AND FAT-FREE MASS

\author{
CORY D. WORTHEY
}

A Thesis Submitted in Partial Fulfillment of the Requirements for the Degree of

MASTER OF SCIENCE

School of Kinesiology and Recreation

ILLINOIS STATE UNIVERSITY

2016 
(C) 2016 Cory D. Worthey 
THE EFFECTS OF TWO DIFFERENT RESISTANCE TRAINING PROTOCOLS WITH SIMILAR VOLUME ON MUSCULAR STRENGTH, MUSCLE THICKNESS, AND FAT-FREE MASS

CORY D. WORTHEY

COMMITTEE MEMBERS:

Kelly R. Laurson, Chair

Daniel J. Dodd

Bradley J. Schoenfeld

Noelle M. Selkow 


\section{ACKNOWLEDGMENTS}

I would like to extend eternal gratitude to Dr. Dan Dodd for actually asking me, "What do you really want to study?" Without his guidance throughout the entirety of the study, this project simply would not have happened. A deep extension of gratitude and humility is extended to Dr. Brad Schoenfeld. Without his prior work, this venture would not have had a framework from which to work. Thank you to Dr. Kelly Laurson for monitoring this project during an extremely busy time in life. A big thanks to Dr. Noelle Selkow for training me on the use of diagnostic ultrasound imaging and her support as the KNR Graduate Program Director. This will forever remain a tool in my arsenal of research diversity.

I am sincerely grateful to Dr. Robert Wildman at Dymatize Nutrition for providing the protein supplement for our participants. Offering free protein to collegeaged research subjects is akin to handing out money. The participants and the research team are thankful for this research donation.

Lastly, I am indebted to our participants and the research team for putting in countless man-hours in pursuit of this resistance training research study. Much like adaptations in well-trained men, the effort-to-benefit ratio for conducting such a study can be daunting, but we did one thing - GSD, all in the name of 'gains.'

C.D.W. 


\section{CONTENTS}

Page

ACKNOWLEDGMENTS $\quad$ i

CONTENTS

TABLES $\quad$ iv

FIGURES $\quad$ V

CHAPTER

I. THE EFFECTS OF TWO DIFFERENT RESISTANCE TRAINING PROTOCOLS WITH SIMILAR VOLUME ON MUSCULAR STRENGTH, MUSCLE THICKENSS, AND FAT-FREE MASS 1

Introduction

Methods $\quad 5$

Subjects $\quad 5$

Resistance Training Procedures 6

Body Composition Assessment Procedures $\quad 7$

Muscle Thickness Measurements $\quad 8$

Muscular Strength Assessments $\quad 8$

$\begin{array}{ll}\text { Statistical Analyses } & 9\end{array}$

$\begin{array}{ll}\text { Results } & 9\end{array}$

$\begin{array}{ll}\text { Muscle Thickness } & 10\end{array}$

Muscular Strength $\quad 10$

Fat-Free Mass $\quad 11$

Discussion 11

Practical Application 15

References $\quad 16$

Tables $\quad 21$

Figures $\quad 24$ 
II. EXTENDED LITERATURE REVIEW 26

Introduction $\quad 26$

$\begin{array}{ll}\text { Volume } & 28\end{array}$

Intensity 31

Training Status $\quad 34$

Resistance Training Interventions $\quad 34$

Gaps in the Literature $\quad 39$

$\begin{array}{ll}\text { References } & 40\end{array}$ 


\section{TABLES}

Table $\quad$ Page

1. Baseline Descriptive Statistics 21

2. Exercise Order for Both Experimental Training Groups 22

3. Average Weekly Volume Loads 23 


\section{FIGURES}

Figure

Page

1. Change in Muscle Thickness Measurements

2. Change in Muscular Strength Measurements 


\section{CHAPTER I}

THE EFFECTS OF TWO DIFFERENT RESISTANCE TRAINING PROTOCOLS

\section{WITH SIMILAR VOLUME ON MUSCULAR STRENGTH,}

\section{MUSCLE THICKNESS, AND FAT-FREE MASS}

\section{Introduction}

For people of all ages, resistance training (RT) is a common mode of exercise used to improve aesthetics, function, and performance. Oftentimes, these goals may include increased muscular strength and muscle hypertrophy. When the magnitude of muscle protein synthesis is greater than muscle protein degradation, skeletal muscle hypertrophy occurs $(18,39)$. Further, muscle hypertrophy plays a large role in muscular strength. Despite the strong correlation with muscle cross-sectional area (CSA) and force production, there is a significant neuromuscular component to the acquisition of muscular strength (16).

General recommendations for training for muscle hypertrophy are the use of moderate intensity workloads and short rest periods between sets while muscular strength training recommendations are the use of high intensity workloads with longer rest periods between sets (3). Although these goals can be achieved through many different types of RT programs, different loading strategies are associated with different musculoskeletal 
and neuromuscular adaptations $(24,38)$, particularly with the manipulation of volume and intensity.

Exercise volume can be defined as the product of repetitions, sets, and the workload for a given exercise or period of training. A greater exercise volume has been shown to be superior in analyses of single- vs. multiple-set protocols for muscular hypertrophy $(23,42)$ and growth hormone responses $(12,32,36)$ possibly due to greater muscle tension, muscle damage, metabolic stress, or a combination of these variables. Exercise volume can be organized by using a split-body routine, wherein specific muscles, muscle groups, or movements are trained per session, or by using a full-body routine with the goal of targeting many or all major muscle groups per session. Weekly training volume can be maintained with fewer sets performed per session by using a splitbody routine when compared to a full-body routine. This format also allows for greater recovery time for muscle groups between training sessions. Exercise volume can be greatly affected by different training frequency preferences.

RT intensity refers to the external workload of a given exercise relative to the individual's 1-repetition maximum (1RM). An inverse relationship exists between exercise intensity and the number of repetitions one can perform with a given workload. It is well-known that regular and consistent high-intensity RT results in increases in maximal muscular strength (14). Initial adaptations to RT mostly occur in the nervous system $(21,28)$, especially in regard to the development of muscular strength (32). Even though there is a strong relationship between CSA and force production (27), there is a significant neural component to the development of strength and power $(16,22)$. It is 
even possible to increase muscle strength through neural adaptations without structural changes within the muscle $(13,19,37,41)$. Experimental and analytical evidence suggests that a dose-response relationship exists between exercise intensity and the rate of gain in muscular strength $(9,17,33)$. Across many studies, the greatest increases in strength occur when individuals use workloads at or near their 1RM and lesser improvements are seen when using lighter loads $(9,11,15,17,25,26,33,35)$. Highintensity training loads are even more crucial for the development of muscular strength for well-trained or advanced individuals (33).

Many studies have compared the effects of strength- vs. hypertrophy-oriented RT protocols. Choi et al. (11) randomly assigned young men (age $29.4 \pm 3.4$ years) into a "power-up type" group performing 5 sets of 90\% 1RM and 3 minutes rest or a "bulk-up type" group performing 9 sets of varying moderate intensities with 30 seconds rest. The "bulk-up type" group experienced greater increases in muscle cross-sectional area (CSA) while the "power-up type" group experienced greater increases in strength. Masuda et al. (26) conducted a similar study with similar results. Important to note is that the RT exercise volume was considerably higher for the "bulk-up type" group. The hypertrophic advantage for the "bulk-up type" groups may have been related to a greater training volume and not dependent on greater relative training intensities.

Assessing muscular adaptations to volume-equated RT protocols, Chestnut and Docherty (10) divided 24 young untrained men performing 4 sets of 4 repetitions or 3 sets of 10 repetitions. At the end of the 10 -week training protocol, significant increase were noted in both groups for strength and CSA, but no differences were seen between 
groups. Campos et al. (9) observed similar changes in CSA with greater maximal strength adaptations occurring in a low (3-5) repetition group compared to a high (9-11) repetition group, supporting the idea that exercise volume may be a dominant factor in skeletal muscle hypertrophic adaptations in untrained men.

Only a few studies to date have compared the muscular adaptations of welltrained men in volume-equated RT protocols. Schoenfeld et al. (35) randomly assigned 17 young men into a strength- (ST) or hypertrophy-style (HT) training group performing 7 sets of 3RM with 3 minutes rest or 3 sets of 10 repetitions with 90 seconds rest, respectively. After 8 weeks, the ST and HT groups experienced similar increases in biceps brachii thickness, but maximal strength was significantly greater for ST compared to HT for 1RM bench press $(p<0.05)$. A trend was noted in favor of ST vs. HT for 1RM back squat but was not statistically significant $(p=0.19)$. These results support the idea that exercise volume may mediate skeletal muscle hypertrophy in well-trained men. Mangine et al. (25) compared the effects of high-volume (4 sets of 10-12 repetitions with 1 minute rest) to high-intensity (4 sets of 3-5 repetitions with 3 minutes rest) protocols. After 8 weeks, the high-intensity group experienced greater changes in upper-body lean mass $(p=0.037)$ and maximal upper-body strength $(p=0.013)$. Reasons for different findings between these two studies lie in the exercise design and volume. Schoenfeld et al. (35) used volume-equated protocols while the high-volume group in Mangine et al. (25) had a greater training volume than the high-intensity group. Additionally, Mangine et al. (25) used the same exercise order for both groups and included more exercises per session than Schoenfeld et al. (35). 
Thus far, RT research findings using well-trained men have been inconsistent. To date, only a few studies have evaluated muscular adaptations using two different RT protocols of similar volume and the same exercise order in well-trained men. The purpose of this study was add experimental data to this specific area of study and to examine the effects of such a protocol on upper- and lower-body muscle thickness, muscular strength, and fat-free mass.

\section{$\underline{\text { Methods }}$}

\section{Subjects}

Eight college-aged men $($ age $=20.8 \pm 0.71$ years; body mass $=82.8 \pm 12.3 \mathrm{~kg}$; height $=1.83 \pm 0.04 \mathrm{~m}$ ) were recruited for participation. Subjects did not have any current musculoskeletal impairments and were not allergic to soy or whey protein. Participants reported being free from consumption of anabolic steroids or any other legal or illegal agents known to increase muscle size over the previous year. All participants were considered to be well-trained, defined as having consistently lifted weights 3 times per week for a minimum of 1 year (RT experience $=3.6 \pm 2.4$ years $)$.

Subjects were pair-matched according to baseline strength and then randomly assigned to 1 of 2 experimental RT protocols: a strength-type group (SG) or a hypertrophy-style group (HG). Baseline descriptive statistics are provided in Table 1. Research study approval was obtained from the Institutional Review Board. Informed consent was obtained from all participants before beginning the study. 


\section{Resistance Training Procedures}

The resistance training protocol consisted of 3 exercises per session 3 days per week for a total of 9 different exercises each week. These included 3 upper-body push movements (flat barbell bench press, incline barbell bench press, and decline Smith machine press), 3 lower-body movements (barbell back squat; barbell glute bridge; and unilateral barbell lunges), and 3 upper-body pull movements (wide-grip cable pull-down, plate-loaded machine row, and close-grip cable pull-down). Both groups performed the same exercises in the same order, one from each movement category, creating a totalbody exercise routine for both groups each training session (Table 2). Subjects were instructed to refrain from participating in any additional resistance-type training throughout the experimental protocol.

Total volume load (total reps x load) was similar between both RT routines to control for the potential impact of volume on muscle thickness (MT). Subjects trained 3 days per week on nonconsecutive days for 9 weeks. All sets were performed to muscular failure, or the inability to perform another concentric repetition while executing proper form, to control for equal set termination criteria for all subjects. The 9-week experimental training period included 4 weeks training as described above, a deloading week during week 5 where the subjects used $75 \%$ of the previous week's workloads for 2 sessions and re-tested all measurements on the last day of the deloading week, and 4 more weeks of the maximal experimental protocol. All routines were directly supervised by the research team, consisting of at least two nationally-certified personal trainers at all times to ensure proper execution of the exercise protocols. Workload adjustments were 
made from set to set and from week to week to promote maximal exertion while maintaining the assigned repetition ranges.

Exercise order was such that fatigued muscle groups were not directly trained from one exercise to the next. Each session followed an upper-body push, lower-body, and upper-body pull exercise sequence. Subjects in SG performed low repetitions (2-4 repetitions with the intended target of 3 repetitions) and subjects in $\mathrm{HG}$ performed moderate repetitions (8-12 repetitions with the intended target of 10 repetitions). Subjects in SG were allotted 3 minutes of rest between sets while subjects in HG were allotted 90 seconds rest between sets per standard guidelines (3).

\section{Body Composition Assessment Procedures}

The BOD POD (COSMED, Chicago, IL, USA) is a seated, air-tight chamber that measures air displacement and the subject's body volume to estimate fat- and fat-free mass (FFM). The BODPOD is a reliable and valid method of assessing body composition and is highly correlated with the "gold standard" methods for body composition assessments $(5,20,29,30)$.

Subjects reported to the Exercise Physiology Laboratory in a 4-hour fasted state. The BODPOD went through a complete calibration the morning of every testing session before any assessments were conducted. Weight was measured using the associated BOD POD scale. Before assessing a subject's body composition, two additional pretesting calibrations were completed before the subject entered the BODPOD. Subjects were required to wear compression shorts and cap to minimize excess pockets of air. Two tests were performed each testing session and the average of the two was reported 
by the BODPOD software if the difference in body volume was not greater than $150 \mathrm{~mL}$, a value set by the manufacturer (5).

\section{Muscle Thickness Measurements}

While lying in the anatomical position, MT measurement sites were marked at one-third and two-thirds of the length in the midline of the muscle or muscle group of interest. After applying a water-soluble transmission gel, all measurements were taken on the right side of the body while the subject lied in the supine or prone positions with the Terason T3000 M-series diagnostic ultrasound imaging system (Terason, Burlington, MA, USA) using B-mode ultrasonography at $12 \mathrm{MHz}$ by a trained technician. The probe was placed parallel to the muscle or muscle group of interest without depressing the skin and subcutaneous adipose tissue. For the forearm flexors and extensors, images were measured from the subcutaneous adipose tissue-muscle interface to the muscle-bone interface. For the rectus femoris and vastus lateralis, images were measured from the subcutaneous adipose tissue-muscle interface to the deep aponeurosis separating the superficial muscles (RF and VL) from the vastus intermedius. This method for the lower-body muscles was chosen due to the $7 \mathrm{~cm}$ depth limitation of the diagnostic ultrasonography imaging unit.

\section{Muscular Strength Assessments}

The barbell bench press (BP) and barbell back squat (BS) using free weights were used to assess upper- and lower-body strength, respectively. National Strength and Conditioning Association (NSCA) protocols were used for 1RM testing procedures for both exercises (4). Subjects performed a general warm-up including 5-10 minutes of 
light cardiovascular exercise and progressive loading warm-up sets of 5 repetitions at $50 \%$ of their perceived $1 \mathrm{RM}$ and $2-3$ repetitions at $60-80 \% 1 \mathrm{RM}$. Single repetitions were performed with increasing weight upon successful attempts with 3-5 minutes rest between 1RM attempts. For 1RMBS, an attempt was considered successful when the subject reached parallel and was able to return to the starting position. Parallel was determined by at least one research assistant with a direct lateral view of the attempt. For 1RMBP, five points of contact must have been maintained throughout the repetition attempt (head, upper back, buttocks, and both feet). Attempts for 1RMBS were completed before moving on to 1 RMBP. Subjects were instructed to use the same hand and feet placements throughout the testing and training sessions.

\section{Statistical Analyses}

Repeated measures ANOVA (SPSS, IBM, Armonk, NY, USA) was used for descriptive statistics, body composition, maximal strength, muscle thickness, fat-free mass, and average weekly volume load. Absolute change, percent change, and effect sizes using Cohen's $d$ ([pretest mean - posttest mean]/pooled standard deviation) were reported for each group for each variable (Microsoft Excel, Redmond, WA, USA). Twotailed alpha was set a priori at 0.05 .

\section{$\underline{\text { Results }}$}

Eight subjects were included in the analyses $(\mathrm{SG} n=4 ; \mathrm{HG} n=4)$. Training session attendance was excellent with an overall attendance of $98.6 \%$. Age, body mass, height, and resistance training experience were not statistically different between groups at baseline. After controlling for body weight, total average weekly volume was $285.2 \pm$ 
$29.4 \mathrm{~kg} \cdot \mathrm{kg}^{-1}$ for SG and $236.0 \pm 61.9 \mathrm{~kg} \cdot \mathrm{kg}^{-1}$ for $\mathrm{HG}$ (Table 3) and were not statistically different $(p=0.24)$. No musculoskeletal injuries or impairments due to the experimental protocols were reported.

\section{Muscle Thickness}

Mean MT changes can be seen in Figure 1. Positive values indicate an increase in muscle thickness and negative values indicate a decrease in muscle thickness. Mean muscle thickness changes from baseline to post-testing for SG and HG, respectively, are as follows: proximal FF: 2.87 vs. $-6.35 \%$; distal FF: -0.55 vs. $-3.72 \%$; proximal FE: 7.99 vs. $-2.49 \%$; distal FE: 19.42 vs. $-2.05 \%$; proximal RF: 3.89 vs. $-0.04 \%$; distal RF: 4.64 vs. $-4.85 \%$; proximal VL: 8.84 vs. $-2.81 \%$; distal VL: 10.30 vs. $5.34 \%$. Significant differences were observed in the proximal forearm flexors in favor of SG compared to HG $(p=0.03)$. No significant differences were observed in any other MT site.

\section{Muscular Strength}

Maximal strength changes can be seen in Figure 2. Baseline values for 1RMBS and 1RMBP were similar between SG and HG. After 9 weeks, results for the back squat increased $16.1 \pm 9.2 \%$ for SG and $5.5 \pm 1.7 \%$ with no significant differences observed in SG $(\mathrm{ES}=0.84 ; 95 \% \mathrm{CI}:-6.119-40.019)$ compared to $\mathrm{HG}(\mathrm{ES}=0.31 ; 95 \% \mathrm{CI}: 0.965-$ $11.535)(p=0.70)$. For the bench press, an increase of $16.0 \pm 13.1 \%$ was observed in SG and $6.9 \pm 2.7 \%$ for $\mathrm{HG}$ with no significant differences observed in $\mathrm{SG}(\mathrm{ES}=0.72 ; 95 \%$ CI: $-10.103-37.253)$ compared to $\mathrm{HG}(\mathrm{ES}=0.36 ; 95 \% \mathrm{CI}: 0.195-11.205)(p=0.17)$. 


\section{Fat-Free Mass}

After 9 weeks, SG experienced an increase in FFM of $1.53 \pm 2.22 \mathrm{~kg}$ and $\mathrm{HG}$ experienced an increase of $0.65 \pm 0.67 \mathrm{~kg}(p=0.16)$. These results did not reach statistical significance between groups, within subjects, or over the course of the intervention.

\section{$\underline{\text { Discussion }}$}

This is one of only a few studies that have assessed muscular adaptations to strength- vs. hypertrophy-style protocols in well-trained men with similar volume loading. The primary finding of this study was that, with the exception of the proximal forearm flexors, changes in muscle thickness were not significantly different between groups. Additionally, contrary to the literature, increases in both measurements of 1RM strength were not significantly greater for SG compared to $\mathrm{HG}$, despite using greater relative intensity workloads.

Overall, changes in MT were not statistically significant. It is possible that 9 weeks of resistance training was not enough to elicit significant changes in MT in welltrained men $(1,11)$. A longer training period may have been necessary to observe significant changes due to the well-trained status of the subjects. These results are in contrast to previous studies using untrained men with unequal volume $(11,26)$, untrained men with equal volume $(9,10)$, and well-trained men with equal volume $(35)$. The results of this study are in agreement with Mangine et al. (25) in that high-intensity RT may have a greater effect on some measures of muscle hypertrophy when compared to moderate-intensity RT. 
The varied results of these similar studies could be related to the experimental exercise protocols, specifically each study's number of exercises, volume load, and the rest periods. In a similar study, the training regimen of Schoenfeld et al. (35) required both groups to perform 3 exercises per training session. Brandenburg and Docherty (7) required only two single-joint exercises per session. The training protocols of Mangine et al. (25) required six single- or multiple-joint exercises per session. The inclusion of more exercises may have elicited greater tissue activation, greater tissue damage in response to RT, and therefore greater changes in muscle morphology.

Contrary to the strong support of the existing literature, the results of this study are not in agreement with the literature stating that higher relative intensity workloads result in greater strength improvements when compared to workloads of lesser relative intensity $(9,11,13,17,25,26,35)$, especially for well-trained or advanced individuals (33). This result may be due to the small sample size of the study.

In regard to rest periods, these results are in agreement with previous studies that have found longer rest periods result in greater increases in some measures of muscle hypertrophy $(8,35)$. Longer rest periods provide the advantage of greater inter-set recovery and allow the exerciser to achieve more repetitions, use a greater workload, or a combination of both. This results in less metabolic stress, a common goal in hypertrophy-style training. Given these training protocols, the benefit of greater mechanical stress appears to outweigh the hypertrophic adaptations attributed to hypertrophy-style training. The results of this study are in contrast with studies that found either no difference or greater increases with short rest periods $(2,40)$. The varied 
results of these studies can be attributed to different definitions of 'short' and 'long' rest intervals. Schoenfeld et al. (35) examined the muscular adaptations in groups of strength-trained men using 1-vs. 3-minute rest intervals and observed a strength and hypertrophy advantage for the group allotted longer rest periods. Ahtiainen et al. (2) compared the effects of 2-vs. 5-minute rest intervals in strength-trained men and found no differences in measures of muscle hypertrophy. Villanueva et al. (40) compared 1- vs. 4-minute rest intervals in older adult men during a 4-week experimental protocol and found greater increases in strength and body composition in the short interval group.

Despite the lack of statistically significant findings, this study employed a few strengths in research design. First, a unified exercise order between both groups allowed the researchers to observe muscular adaptations in total-body routines only, eliminating the accumulated metabolic stress associated with split-body part routines. According to our data, this exercise organization was enough to elicit negative effects on MT for subjects in the hypertrophy-style training group, indicating that hypertrophy-style loading with a total-body routine may not be an effective RT strategy to amass significant muscle hypertrophy. Second, the inclusion of air displacement plethysmography in addition to MT measurements allowed the researchers to refer local measures of muscle hypertrophy to a global assessment of FFM. In the example of HG, negative average changes in MT were observed with a concomitant average increase in FFM, raising the possibility of increases in FFM in muscle groups not included in the present MT analysis. It is important to note, however, that FFM assessments include muscle, water, bone, organs, and other non-fat tissues, a distinction the BOD POD is unable to distinguish. The 
positive changes in FFM may have been due to increases in these other non-muscle tissues. Third, despite the great physical demand of training to failure in the present protocols, no musculoskeletal injuries were reported during the 9-week training period. Previously, a similar training protocol experienced a $10 \%$ subject mortality rate over the course of 8 weeks of training to failure three days per week (35). The authors attribute this to the addition of a deloading week halfway through the experimental protocol. Deloading or tapering can be accomplished by systematically decreasing exercise intensity, volume, frequency, or a combination of these variables over the course of a given training period for the purpose of optimizing performance and enhanced recovery $(6,31)$. Symptoms of frequent high-demand resistance training may be mediated by the addition of a deloading or taper phase.

Several limitations were present in this study and are important to note when analyzing the results. First, the method used in this study to calculate volume load (reps $\mathrm{x}$ load) does not accurately calculate work performed during exercise as it does not take into account the distance travelled per load per exercise nor the actual forces applied during each movement. Second, Average weekly volume loads were not as similar as those used in a similar study (35). Third, exercise selection included two lower-body exercises that almost all subjects reported not performing regularly before participating in this study. This may have limited the hypertrophic effects of the lower-body muscles via the timecourse of neuromuscular and musculoskeletal adaptations to novel RT exercises. Fourth, the duration of the study was relatively short. Many measurements of strength and hypertrophy did not reach statistical significance. A longer duration may have been 
necessary to observe significant changes in muscle thickness $(1,11)$. Fifth, although four muscle areas were selected, the MT findings are not globally representative of all muscles or muscle groups. There is the possibility that greater changes in MT could have occurred in other muscles such as pectoralis major, latissimus dorsi, or biceps femoris. Lastly, these findings are specific to young, well-trained men and cannot be generalized to other populations. Further research is required to elucidate the effects of specific loading strategies in other populations.

\section{Practical Application}

In conclusion, the results of this study are a product of careful protocol designs. Based on our results, using a total-body exercise routine with strength- and hypertrophystyle loading strategies with similar volume, high-intensity RT with long rest periods may have a greater effect on muscular strength and hypertrophy than moderate-intensity RT with short rest periods. These results may be specific to well-trained men. Nine weeks of these experimental protocols was not long enough to elicit statistically significant changes, but trends show diverging muscular adaptations between groups. To further understand the effects of different RT volume, intensity, rest intervals, and exercise order on well-trained men, further research is needed with different combinations of these variables. 


\section{REFERENCES}

1. Abe TD, DeHoyos DV, Pollock ML, and Garzarella L. Time course for strength and muscle thickness changes following upper and lower body resistance training in men and women. Eur J Appl Physiol 81: 174-180, 2000.

2. Ahtiainen JP, Pakarinen A, Alen M, Kraemer WJ, and Hakkinen K. Short vs. long rest period between the sets in hypertrophic resistance training: influence on muscle strength, size, and hormonal adaptations in trained men. J Strength Cond Res 19: 572-582, 2005.

3. American College of Sports Medicine. American College of Sports Medicine position stand. Progression models in resistance training for healthy adults. Med Sci Sports Exerc 41(3): 687-708, 2009.

4. Baechle, TR and Earle, RW. Essentials of Strength and Conditioning. In: Anonymous. Champaign, IL: Human Kinetics, 2008.

5. Ball SD. Interdevice variability in percent fat estimates using the BOD POD. Eur J Clin Nutr 59(9): 996-1001, 2005.

6. Bishop PA, Jones E, and Woods AK. Recovery from training: A brief review. $J$ Strength Cond Res 22(3): 1015-1024, 2008.

7. Brandenburg JE, and Docherty D. The effects of accentuated eccentric loading on strength, muscle hypertrophy, and neural adaptations in trained individuals. $J$ Strength Cond Res 16: 25-32, 2002.

8. Buresh R, Berg K, and French J. The effect of resistive exercise rest interval on hormonal response, strength, and hypertrophy. J Strength Cond Res 23: 62-71, 2009.

9. Campos GER, Luecke TJ, Wendeln HK, Toma K, Hagerman FC, Murray TF, Ragg KE, Ratamess NA, Kraemer WJ, and Staron RS. Muscular adaptations in response to three different resistance-training regimens: specificity of repetition maximum training zones. Eur J Appl Physiol 88(1-2): 50-60, 2002. 
10. Chestnut J, and Docherty D. The effects of 4 and 10 repetition maximum weighttraining protocols on neuromuscular adaptations in untrained men. J Strength Cond Res 13: 353-359, 1999.

11. Choi J, Takahashi H, Itai Y, and Takamatsu K. The difference between effects of "power-up type" and "bulk-up type" strength training exercises: With special reference to muscle cross-sectional area. Jpn J Phys Fitness Sports Med 47: 119-129, 1998.

12. Craig B, and Kang H. Growth hormone release following single versus multiple sets of back squats: Total work versus power. J Strength Cond Res 8: 270$275,1994$.

13. Enoka RM. Neuromechanical basis of kinesiology. Human Kinetics, Champaign, IL. 1988.

14. Fleck SJ, and Kraemer WJ. Resistance training: physiological responses and adaptations (part 3). Phys Sportsmed 16(5): 63-73, 1988.

15. Fry AC. The role of resistance exercise intensity on muscle fibre adaptations. Sports Med 34(10): 663-679, 2004.

16. Gabriel DA, Kamen G, and Frost G. Neural adaptations to resistive exercise: Mechanisms and recommendations for training practices. Sports Med 36: 133 149, 2006.

17. Harber MP, Fry AC, Rubin MR, Smith JC, and Weiss LW. Skeletal muscle and hormonal adaptations to circuit weight training in untrained men. Scand J Med Sci Sports 14(3): 176-185, 2004.

18. Hill M, and Goldspink G. Expression and splicing of the insulin-like growth factor gene in rodent muscle is associated with muscle satellite (stem) cell activation following local tissue damage. J Physiol 549: 409-418, 2003.

19. Hong A, Hong S, and Shin Y. Effects of resistance training on muscle strength, endurance, and motor unit according to ciliary neurotrophic factor polymorphism in male college students. J Sports Sci Med 13(3): 680-688, 2014.

20. Johnson KE, Miller B, Gibson AL, McLain TA, Juvancic-Heltzel JA, Kappler RM, and Otterstetter R. A comparison of dual-energy X-ray absorptiometry, air displacement plethysmography and A-mode ultrasound to assess body composition in college-age adults. Clin Physiol Funct Imaging. Advance online publication. doi: 10.1111/cpf.12351. 2016. 
21. Kraemer WJ. Endocrine responses to resistance exercise. Med Sci Sports Exerc 20(5 suppl.): S152-S157, 1988.

22. Kraemer W J, Fleck SJ, Dziados JE, Hayman EA, Marchitelli LJ, Gordon SE, Mello R, Frykman PN, Koziris LP, and Triplett NT. Changes in hormonal concentrations after different heavy-resistance exercise protocols in women. $J$ Appl Physiol 75: 594-604, 1993.

23. Krieger JW. Single vs. multiple sets of resistance exercise for muscle hypertrophy: A meta-analysis. J Strength Cond Res 24: 1150-1159, 2010.

24. MacDougall JD, Sale DG, Always SE, and Sutton JR. Muscle fiber number in biceps brachii in bodybuilders and control subjects. J Appl Physiol 57: 13991403, 1984.

25. Mangine GT, Hoffman JR, Gonzalez AM, Townsend JR, Wells AJ, Jajtner AR, Beyer KS, Boone CH, Miramonti AA, Wang R, LaMonica MB, Fukuda DH, Ratamess NA, and Stout JR. The effect of training volume and intensity on improvements in muscular strength and size in resistance-trained men. Physiol Rep 3(8): e12472, 2015.

26. Masuda K, Choi JY, Shimojo H, and Katsuta S. Maintenance of myoglobin concentration in human skeletal muscle after heavy resistance training. Eur J Appl Physiol Occup Physiol 79(4): 347-352, 1999.

27. Maughan RJ, Watson JS, and Weir J. Strength and cross-sectional area of human skeletal muscle. J Physiol 338: 37-49, 1983.

28. McCall GE, Byrnes WC, Fleck SJ, Dickinson A, and Kraemer WJ. Acute and chronic hormonal responses to resistance training designed to promote muscle hypertrophy. Can J Appl Physiol 24(1): 96-107, 1999.

29. McCrory MA, Gomez TD, Bernauer EM, and Molé PA. Evaluation of a new air displacement plethysmograph for measuring human body composition. Med Sci Sports Exerc 27(12): 1686-1691, 1995.

30. Moon JR, Tobkin SE, Smith AE, Roberts MD, Ryan ED, Dalbo VJ, Lockwood CM, Walter AA, Cramer JT, Beck TW, and Stout JR. Percent body fat estimations in college men using field and laboratory methods: A threecompartment model approach. Dyn Med. doi: 10.1186/1476-5918-7-7. 2008.

31. Mujika I, and Padilla S. Scientific bases for precompetition tapering strategies. Med Sci Sports Exerc 35(7): 1182-1187, 2003. 
32. Mulligan SE, Fleck SJ, Gordon SE, and Koziris LP. Influence of resistance exercise volume on serum growth hormone and cortisol concentration in women. J Strength Cond Res 10: 256-262, 1996.

33. Peterson MD, Rhea MR, and Alvar BA. Applications of the dose-response for muscular strength development: A review of meta-analytic efficacy and reliability for designing training prescription. J Strength Cond Res 19(4): 950958, 2005.

34. Schoenfeld, BJ, Pope, ZK, Benik, FM, Hester, GM, Sellers, J, Nooner, JL, Schnaiter, JA, Bond-Williams, KE, Carter, AS, Ross, CL, Just, BL, Henselmans, M, and Krieger JW. Longer inter-set rest periods enhance muscle strength and hypertrophy in resistance-trained men. J Strength Cond Res. Advance online publication. doi: 10.1519/JSC.0000000000001272. 2015.

35. Schoenfeld BJ, Ratamess NA, Peterson MD, Contreras B, Sonmez GT, and Alvar BA. Effects of different volume-equated resistance training loading strategies on muscular adaptations in well-trained men. J Strength Cond Res 28(10): 2909-18, 2014.

36. Smilios I, Pilianidis T, Karamouzis M, and Tokmakidis SP. Hormonal responses after various resistance exercise protocols. Med Sci Sport Exerc 35: 644-654, 2003.

37. Staron RS, Karapondo DL, Kraemer WJ, Fry AC, Gordon SE, Falkel JE, Hagerman FC, and Hikida RS. Skeletal muscle adaptations during early phase of heavy-resistance training in men and women. J Appl Physiol 76(3): 1247$55,1994$.

38. Tesch PA, and Larsson L. Muscle hypertrophy in bodybuilders. Eur J Appl Physiol Occup Physiol 49: 301-306, 1982.

39. Toigo $\mathrm{M}$ and Boutellier U. New fundamental resistance exercise determinants of molecular and cellular muscle adaptations. Eur J Appl Physiol 97: 643-663, 2006.

40. Villanueva MG, Lane CJ, and Schroeder ET. Short rest interval lengths between sets optimally enhance body composition and performance with 8 weeks of strength resistance training in older men. Eur J Appl Physiol 115: 295-308, 2015.

41. Wilmore JH, Costill DL, and Kenney LW. Physiology of sport and exercise. 4th ed. Human Kinetics, Champaign, IL. 2007. 
42. Wolfe BL, LeMura LM, and Cole PJ. Quantitative analysis of single- vs. multiple-set programs in resistance training. J Strength Cond Res 18: 35-47, 2004. 


\section{TABLES}

\begin{tabular}{|lcc|}
\hline Table 1 \\
Baseline Descriptive Statistics \\
\hline$\underline{\text { Descriptor }}$ & $\underline{\mathrm{SG}}$ & $\underline{\mathrm{HG}}$ \\
Age (y) & $21.0 \pm 0.8$ & $20.5 \pm 0.6$ \\
Height (m) & $1.83 \pm 0.04$ & $1.83 \pm 0.04$ \\
Weight (kg) & $83.7 \pm 7.1$ & $82.0 \pm 17.3$ \\
Fat-free mass (kg) & $71.0 \pm 4.5$ & $65.0 \pm 6.0$ \\
Resistance training & $4.0 \pm 2.9$ & $3.1 \pm 2.0$ \\
experience (y) & & \\
\hline
\end{tabular}


Table 2

Exercise Order for Both Experimental Training Groups

Session 1 $\underline{\text { Session } 2}$

Session 3

Flat bench press

Incline bench press

Decline Smith press

Barbell back squat

Glute bridge Unilateral barbell lunges

Wide-grip pull-down

Plate-loaded row

Close-grip pull-down 


\begin{tabular}{|c|c|c|}
\hline \multicolumn{3}{|c|}{$\begin{array}{l}\text { Table } 3 \\
\text { Average Weekly Volume Loads }\end{array}$} \\
\hline Exercise & $\underline{\mathrm{SG}}$ & $\underline{\mathrm{HG}}$ \\
\hline Flat bench press & $1,737(20.6)$ & $1,702(21.3)$ \\
\hline Back squat & $2,279(27.3)$ & $2,348(29.5)$ \\
\hline Wide-grip pull-down & $2,053(24.5)$ & $1,552(19.6)$ \\
\hline Incline bench press & $1,536(18.2)$ & $1,452(18.1)$ \\
\hline Glute bridge & $4,020(55.5)$ & $3,313(41.8)$ \\
\hline Plate-loaded row & $2,679(32.2)$ & $1,725(21.9)$ \\
\hline Decline Smith press & $2,306(27.4)$ & $2,031(25.4)$ \\
\hline Unilateral barbell lunges & $4,416(53.3)$ & $3,035(39.2)$ \\
\hline Close-grip pull-down & $2,186(26.2)$ & $1,520(19.2)$ \\
\hline Totals & $23,212(285.2)$ & $18,678(236.0)$ \\
\hline \multicolumn{3}{|c|}{$\begin{array}{l}\text { Average weekly volume loads for each exercise displayed as } \\
\text { absolute values in } \mathrm{kg} \text { and scaled by body weight in } \mathrm{kg} \cdot \mathrm{kg}^{-1} \\
\text { (shown in parentheses) for the strength-style (SG) and } \\
\text { hypertrophy-style (HG) groups. }\end{array}$} \\
\hline
\end{tabular}




\section{FIGURES}

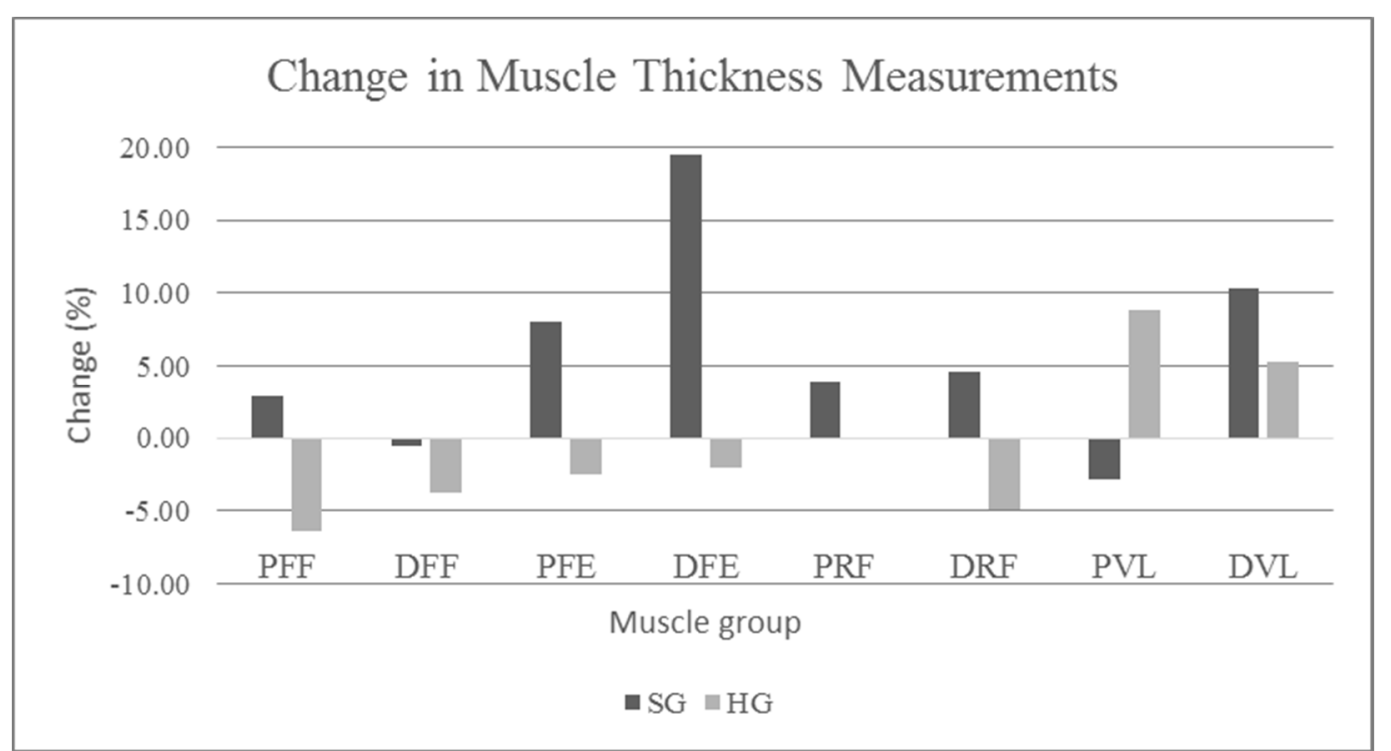

Figure 1. Change in Muscle Thickness Measurements. Changes in muscle thickness at the proximal forearm flexors (PFF), distal forearm flexors (DFF), proximal forearm extensors (PFE), distal forearm extensors (DFE), proximal rectus femoris (PRF), distal rectus femoris (DRF), proximal vastus lateralis (PVL), and distal vastus lateralis (DVL) for strength-style (SG) and hypertrophy-style (HG) groups from baseline to postintervention. 


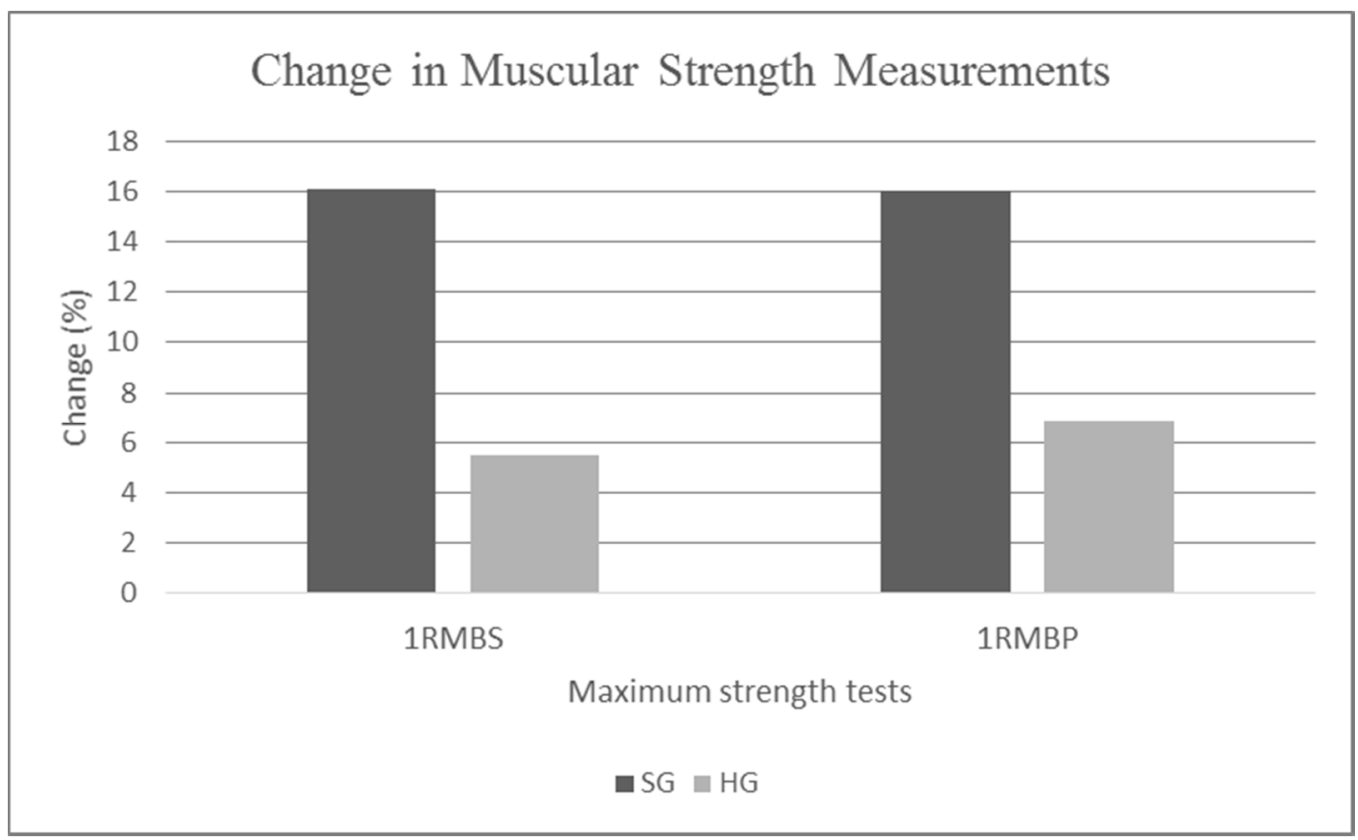

Figure 2. Change in Muscular Strength Measurements. Changes in one repetition maximum for the barbell back squat (1RMBS) and flat barbell bench press (1RMBP) for the strength-style (SG) and hypertrophy-style (HG) groups. 


\section{CHAPTER II}

\section{EXTENDED LITERATURE REVIEW}

\section{$\underline{\text { Introduction }}$}

For people of all ages, resistance training (RT) is a common mode of exercise used to improve one's aesthetics, function, and performance. RT often results in an increase in muscle size and strength through a wide variety of loading strategies. Although these goals can be achieved through many different kinds of RT programs, it is logical to assume that some programs are better than others at helping exercisers achieve their personal goals. The manipulation of many variables associated with RT is the essence of exercise programming for the purpose of specific neuromuscular and musculoskeletal adaptations. Recent research has made a dent in trying to figure out which types of programs are more effective for working towards particular goals than others, but gaps still remain as to the best approaches for increasing muscle size and strength for particular populations.

Muscle hypertrophy is defined as the increase in size of skeletal muscle fibers and is in contrast to skeletal muscle hyperplasia, the increase in the number of myofibers within a muscle. When the magnitude of muscle protein synthesis is greater than muscle protein degradation, skeletal muscle hypertrophy occurs $(23,76)$. Muscle fibers are sensitive to many stimuli that signal anabolic processes, resulting in the increase in the 
size of a muscle fiber $(56,76)$. The three primary stimuli known to induce hypertrophic adaptations in skeletal muscle are mechanical tension, muscle damage, and metabolic stress $(15,28,64,77)$.

Mechanical tension within a muscle can be imposed by external loading. With sufficient nutrient availability, chronic mechanical loading of the musculoskeletal system results in an increase in mass while chronic unloading results in muscle atrophy, or a decrease in mass $(19,26)$. Mechanical tension induced by RT is thought to cause paracrine and autocrine mechano-chemical responses within muscle fibers and their satellite cells (76). These responses catalyze many growth processes that ultimately contribute to contractile muscle hypertrophy (56). Mechanical tension is a potent stimulator of muscle hypertrophy but may elicit its greatest effects when combined with other hypertrophic stimuli (56).

The repair and growth processes of skeletal muscle tissue in response to localized damage are inflammatory in nature. Following damage to the muscle fiber, macrophages and cytokines migrate to the location to clear cellular and metabolic debris via diapedesis $(15,23,49)$. Evidence suggests that local cytokines play a significant role in skeletal muscle hypertrophy $(44,51,63)$. Satellite cells leave their former quiescent state and migrate to fuse onto damaged muscle cells $(76,78)$ thus initiating the early stages of skeletal muscle hypertrophy.

The long-held belief behind bodybuilding-style training is that the use of moderate workloads generates metabolic stress within the muscle milieu causing hypertrophic adaptations to occur, notably in noncontractile components and fluid 
content of muscle $(34,83)$. Indeed, studies have supported the idea that metabolic stress induces anabolic responses associated with exercise $(53,61,66)$. Exercise-induced metabolites include lactate, hydrogen ions, inorganic phosphate, creatine, and many others as a result of anaerobic glycolysis $(69,74)$. Other stress-induced mechanisms may include local hormone activity, cell swelling, the presence of reactive oxygen species, and an increase in growth transcription factors $(20,21,70)$. A few studies have showed that different hypertrophic adaptations may occur as a result of different RT loading strategies $(34,75)$, particularly with the manipulation of volume and intensity.

\section{Volume}

Exercise volume can be defined as the product of repetitions, sets, and the workload for a given exercise or period of training. A greater exercise volume has shown superiority in analyses of single- vs. multiple-set protocols in training for muscular hypertrophy $(32,82)$ and growth hormone responses $(12,42,65)$. This could be due to greater total muscle tension, muscle damage, metabolic stress, or a combination of these variables.

Periodization is the controlled manner in which exercise program variables are manipulated over time. Classical, or linear, periodization can be described as highvolume, low-intensity initial training and gradually working towards low-volume, highintensity training (3). Employing these systematic changes allows an exerciser to train through a spectrum of loading strategies to elicit a variety of training adaptations. Linear periodization has demonstrated superior results for increasing maximal strength compared to nonperiodized training protocols $(68,80)$. Reverse periodization has been 
shown to be superior for increasing local muscular endurance (13) and when compared to other periodization models with equal volume and intensity (52). Undulating, or nonlinear, periodization varies the exercise intensity and volume within a cycle, using light, moderate, and heavy loads in a systematic or random manner. Undulating periodization has shown an advantage over periodized and nonperiodized multiple-set protocols (4) and has been demonstrated to elicit greater strength gains compared to linear periodization over the course of 12 weeks of a RT protocol (52).

In a meta-analysis examining whether single or multiple sets of RT are more effective for muscular hypertrophy, single sets showed an effect size of 0.25 while multiple sets showed an effect size of 0.35 (32). According to Cohen's classifications, both effect sizes are small but multiple sets were associated with a $40 \%$ greater effect size for hypertrophy than single sets (32), indicating superiority for greater exercise volume for muscle hypertrophy. In a similar meta-analysis for muscular strength (31), single sets resulted in a moderate effect size (0.54) compared to a large effect size (0.80) for multiple sets. This is in agreement with a 2005 meta-analysis of the dose-response for muscular strength development (47) which concluded that 4 sets and 8 sets per body part elicited maximal strength gains in untrained and trained populations, respectively.

Exercise volume can be organized by using a split-body routine, wherein specific muscles, muscle groups, or movements are trained per session, or by using a full-body routine with the goal of targeting many or all major muscle groups per session. Weekly training volume can be maintained with fewer sets performed per session by using a splitbody routine when compared to a full-body routine. This format also allows for greater 
recovery time for muscle groups between training sessions. Exercise volume can be greatly affected by different training frequency preferences.

In the context of weekly training frequency, Schoenfeld et al. (59) investigated the effects of training muscle groups once per week using a split-body routine vs. three days per week using a total-body routine with equal training volume. The 20 subjects were classified as well-trained (greater than one year of current resistance training experience) and from a university population (age $=23.5 \pm 2.9$ years). Subjects were randomly assigned to a group performing a split- or total-body routine training three days per week. All subjects performed the same 21 exercises over the course of three sessions per week performing 2-3 sets of 8-12 repetitions to concentric failure. The study was carried out for 8 weeks. Subjects were tested pre- and post-study for 1 repetition maximum (RM) strength in the bench press and back squat and muscle thickness (MT) measurements of the forearm flexors, forearm extensors, and vastus lateralis via diagnostic ultrasound imaging. The full-body training group experienced greater increases in forearm flexor MT compared to the split-body training group (6.5 vs. $4.4 \%$, respectively). Forearm extensor MT did not reach statistical significance, however the effect size was greater for the full-body training group compared to the split-body training group ( 0.90 vs. 0.46 , respectively). Similarly, the effect size for quadriceps MT was greater for the full-body training group compared to the spit-body training group ( 0.70 vs. 0.18 , respectively). These results indicate that a greater weekly training frequency per muscle group may be superior when training for muscle hypertrophy in well-trained men. 


\section{$\underline{\text { Intensity }}$}

RT intensity refers to the external workload of a given exercise relative to the individual's 1-repetition maximum (1RM). An inverse relationship exists between exercise intensity and the number of repetitions one can perform with a given workload. It is well-known that regular and consistent high-intensity RT results in increases in maximal muscular strength (16). Initial adaptations to RT mostly occur in the nervous system $(29,38)$, especially in regards to the development of muscular strength (42). Even though there is a strong relationship between CSA and force production (37), there is a significant neural component to the development of strength and power $(18,30)$. It is even possible to increase muscle strength through neural adaptations without structural changes within the muscle $(14,25,67,81)$.

Experimental and analytical evidence suggests that a dose-response relationship exists between exercise intensity and the rate of gain in muscular strength $(7,22,47)$. Across many studies, the greatest increases in strength occur when individuals use workloads at or near their 1RM and lesser improvements are seen when using lighter loads $(7,10,17,22,35,36,47,60)$. High-intensity training loads are even more crucial for the development of muscular strength for well-trained or advanced individuals (47).

Skeletal muscle hypertrophy appears to be related, in part, to relative RT intensity (17). Popular opinion states that a minimum intensity threshold of greater than $60 \%$ of $1 \mathrm{RM}$ is necessary to cause significant muscular hypertrophy $(3,39,79)$. This relative intensity threshold may be necessary to impose enough of a stimulus to cause hypertrophic adaptations to occur in all fiber types. Though varied, Type I and Type II 
skeletal muscle fibers generally experience greater hypertrophic adaptations when using higher relative intensities (17).

Some have challenged the notion of a minimum intensity threshold necessary for significant muscle hypertrophy to occur, suggesting that hypertrophy may rather be dependent upon RT being performed to volitional concentric muscular failure. Using loads less than 50\% 1RM, several researchers have reported significant changes using such protocols $(6,58,79)$. When using unequal training volumes, all studies but one (62) found similar muscular hypertrophy between high- and low-load RT $(33,40,46,50,58$, $71,72)$. When training volume is equal, the work-to-benefit ratio of high-load RT appears to be superior $(7,24)$. It is important to note that the full spectrum of muscle fiber types may not be recruited enough to experience hypertrophy in all fiber types (57). Further research is necessary for the discussion of fiber type- and relative intensityspecific hypertrophic adaptations.

In a 2015 study, Schoenfeld et al. (58) set out to examine the effects of low- vs. high-load resistance training on strength and hypertrophy in well-trained men with results that challenge the notion of a minimal relative intensity threshold necessary for skeletal muscle hypertrophy. Eighteen young well-trained men were randomly assigned to one of two groups: a low-load RT routine (LL; 25-35 repetitions per set per exercise) or a highload RT routine (HL; 8-12 repetitions per set per exercise). Both groups performed 3 sets for 7 exercises 3 times per week for 8 weeks. All sets were performed to concentric muscular failure. These loading strategies are such that the training volume for LL was approximately three times that of HL. Pre- and post-training measurements included 
maximal strength via 1RM back squat and bench press; muscle thickness measurements of the elbow flexors, elbow extensors, and quadriceps via diagnostic ultrasound imaging; and muscle endurance via 50\% 1RM bench press for maximal repetitions.

After 8 weeks of training, both HL and LL groups experienced significant muscle thickness increases of the elbow flexors (5.3 vs. 8.6\%), elbow extensors (6.0 vs. 5.6\%), and the quadriceps femoris (9.3 vs. 9.5\%) with no significant differences between groups. Changes in maximal back squat strength were significantly greater for HL compared to LL (19.6 vs. $8.8 \%)$ and a similar trend was noted for the bench press (6.5 vs. $2.0 \%)$. Overall, these results indicate significant muscle hypertrophy can occur when using RT loads of approximately $30-50 \% 1 \mathrm{RM}$, well below the generally accepted minimal threshold of $65 \% 1 \mathrm{RM}$, with significant concomitant increases in lower-body strength.

The authors recognize the possibility of fiber-type specific hypertrophy to account for the significant muscle thickness changes in the LL group (58). Given that no subjects in LL reported using repetition schemes greater than 15 repetitions in their normal prestudy training routines, these subjects may have experienced a novel training stimulus in response to performing RT exercise sets using 25-35 repetitions. This idea is supported by Netreba et al. (43) who found that training using loads of $80-85 \% 1 \mathrm{RM}$ preferentially increased muscle CSA of fast-twitch fibers whereas training using loads of 50\% 1RM preferentially increased muscle CSA of slow-twitch fibers. This hypothesis would be consistent with findings from Mitchell et al. (40) who found that the magnitude of change for type I fiber CSA was greater using low-load RT (23 vs. 16\%), although those results were not significant due to low statistical power. 


\section{$\underline{\text { Training Status }}$}

Prior to assessing skeletal muscle adaptations to a RT protocol, an individual's prior and current training experience must be understood, or better yet quantified. An inverse relationship exists between resistance training experience and the rate of gains of muscle hypertrophy, strength, and anabolic signaling $(11,45,47,56)$. For previously untrained individuals, neural adaptations are responsible for increases in muscular strength performance during the initiation of a RT protocol (41). Within six weeks of initiation to RT, skeletal muscle hypertrophy manifests (48). Thereafter, a conjunction of neural adaptations and hypertrophy attribute to strength gains. Once adaptation occurs, a greater stimulus must be applied to recruit the same or more muscle fibers (3).

As an individual's resistance training experience increases, exercise volume and intensity should progressively and systematically increase over time in order to maximize skeletal muscle adaptations (3). Trained muscle fibers are morphologically $(37,54)$ and functionally $(1,27,54,55)$ different than untrained muscle fibers. Trained muscles also display reduced exercise-specific anabolic cell signaling behaviors in humans (11) and rodents (45), which can return after a short period of using reduced training loads (45). There is a clear difference in the effort-to-benefit curve among untrained, recreationally trained, and advanced or athletic populations (47) as it becomes increasingly more difficult to gain muscle mass with increasing resistance training experience (56).

\section{$\underline{\text { Resistance Training Interventions }}$}

A few studies have sought to compare the effects of strength- vs. hypertrophyoriented RT protocols. Key differences in these studies involve using trained or 
untrained men and with equal or unequal RT volume. These studies highlight the differences between these two key factors. Choi et al. (10) divided young men (age 29.4 \pm 3.4 years) into a "power-up type" group performing 5 sets of $90 \% 1 \mathrm{RM}$ and 3 minutes rest or a "bulk-up type" group performing 9 sets of varying moderate intensities with 30 seconds rest. These subjects were not classified as having current training experience. Both groups performed isotonic knee extensions twice a week for 8 weeks. The "bulk-up type" group experienced greater increases in muscle cross-sectional area (CSA) while the "power-up type" group experienced greater increases in strength. Masuda et al. (36) conducted a similar study with similar results. Important to note is that the RT exercise volume was considerably higher for the "bulk-up type" group. The hypertrophic advantage for the "bulk-up type" groups may have been related to a greater training volume and not dependent on greater relative training intensities.

Assessing muscular adaptations to volume-equated RT protocols, Chestnut and Docherty (9) divided 24 young untrained men performing 4 sets of 4 repetitions or 3 sets of 10 repetitions. All sets were performed to failure and training was carried out 3 times per week for 10 weeks. The forearm extensors and flexors were assessed for strength, CSA via magnetic resonance imaging, specific tension, and circumference measurements. At the end of the 10-week training protocol, significant increase were noted in both groups for strength and CSA, but no differences were seen between groups. These results are specific to responses seen in untrained muscle according to this RT loading protocol, therefore these results cannot be generalized to well-trained men. 
Campos et al. (7) assessed lower-body muscle adaptations to three different loading strategies: a low repetition group (4 sets of 3-5RM with 3 minutes rest), an intermediate repetition group (three sets of 9-11RM with 2 minutes rest), and a high repetition group ( 2 sets of 20-28RM with 1 minute rest). All subjects performed the leg press, squat, and knee extensions 2 days per week during the initial four weeks and then 3 days per week for the final 4 weeks. Subjects were tested for maximal strength (1RM), local muscular endurance (maximal repetitions at $60 \% 1 \mathrm{RM}$ ), and various cardiorespiratory measures. In this roughly volume-equated set-up, all groups experienced similar changes in CSA while greater maximal strength adaptations occurred in the low repetition group compared to the two other groups, supporting the idea that exercise volume may be a dominant factor in skeletal muscle hypertrophic adaptations in untrained men.

Few studies exist that have assessed skeletal muscle adaptations in men with advanced prior RT experience. Using a volume-equated design with well-trained men, Schoenfeld et al. (60) randomly divided 17 young men into a strength-type training group (ST) performing 7 sets of 3 repetitions with 3-minutes rest between sets or a hypertrophytype training group (HT) performing 3 sets of 10 repetitions with 90 seconds rest between sets. Both groups performed the same exercises but in different routine splits. ST's exercise sessions were total-body exercise routines following a upper-body push, leg, and upper-body pull order. HT's exercise sessions were split-body exercise routines, performing all three upper-body push movements on one day, all leg movements the next day, and all upper-body pull movements on the last training day of the week. All subjects 
trained 3 days per week for 8 weeks. Muscle thickness of the biceps brachii via diagnostic ultrasound imaging and maximal strength via $1 \mathrm{RM}$ back squat and bench press were assessed before and after the training period.

After 8 weeks, the ST and HT groups experienced a 12.7 and $12.6 \%$ increase in biceps brachii thickness, respectively. After adjusting for baseline values, maximal strength adaptations were greater and significant for ST compared to HT for 1RM bench press $(p<0.05)$. A trend was noted in favor of ST vs. HT for 1RM back squat $(\beta=15.0$; $p=0.19)$. Given these results, exercise volume may mediate skeletal muscle hypertrophy in well-trained men. Additionally, in agreement with most of the literature, highintensity loading appears to increase maximal strength to a greater degree than moderateor low-intensity resistance training.

In a 2015 study, Mangine et al. (35) examined muscular size and strength responses to two training protocols of unequal volume. Twenty-nine resistance-trained men were randomly assigned to a high-volume (VOL; 4 sets of $10-12$ repetitions at $\sim 70 \%$ 1RM with 1 minute rest) or high-intensity (INT; 4 sets of 3-5 repetitions at $\sim 90 \% 1 \mathrm{RM}$ with 3 minutes rest) protocol. After a two-week preparatory exercise familiarization period, subjects trained four times per week for 8 weeks. Pre- and post-measurements included lean tissue mass via dual energy $\mathrm{x}$-ray absorptiometry (DEXA), muscle CSA and thickness via diagnostic ultrasound imaging, and 1RM strength in the back squat and bench press.

Following the 8-week training protocol, results showed that INT experienced greater changes in lean arm mass compared to VOL $(5.2 \pm 2.9 \%$ vs. $2.2 \pm 5.6 \% ; p=$ 
0.037 ) with $93.3 \%$ of INT subjects experienced changes in lean arm mass greater than the minimal difference $(\mathrm{MD}=0.23 \mathrm{~kg})$ and only $64.3 \%$ of VOL subjects experiencing changes greater than the minimal difference. Similar trends were noted in total lean body mass ( $\mathrm{MD}=1.53 \mathrm{~kg} ; 60.0$ vs. $35.7 \%)$, lean leg mass $(\mathrm{MD}=0.91 \mathrm{~kg} ; 46.7$ vs. $21.4 \%)$, and vastus lateralis $\mathrm{CSA}\left(\mathrm{MD}=3.05 \mathrm{~cm}^{2} ; 50.0\right.$ vs. $\left.21.4 \%\right)$. Significant increases in strength were observed in the bench press for both VOL (pre: $104.5 \pm 19.2 \mathrm{~kg}$; post: $110.9 \pm 17.5 \mathrm{~kg} ; p=0.018$ ) and INT (pre: $108.8 \pm 31.8 \mathrm{~kg} ;$ post: $123.8 \pm 34.1 \mathrm{~kg} ; p<$ $0.001)$, with significantly greater improvements for INT than VOL $(p=0.013)$.

The results of this study indicate that high-intensity, low-volume RT improves maximal strength greater than moderate-intensity, high-volume RT while producing a similar magnitude of muscle hypertrophy. Some measures of muscle size, however, indicate a possible hypertrophic advantage to using greater relative intensity training loads despite a lower training volume. Key differences between Schoenfeld et al. (60) and Mangine et al. (35) may lie within tissue activation via exercise selection and the number of exercises included in each training session. The training regimen of Schoenfeld et al. (60) required both groups to perform 3 exercises per training session. Similarly, Brandenburg and Docherty (5) required only two single-joint exercises per session. The training protocols of Mangine et al. (35) required six single- or multiplejoint exercises per session. The inclusion of more exercises likely caused greater tissue activation, greater tissue damage in response to RT, and therefore greater changes in muscle morphology. 
In regards to lower-body hypertrophic adaptations, the authors state the possibility of 8 weeks not being a long enough training period to realize significant changes in lower-body musculature, especially that of resistance-trained men $(1,8,73)$. In the present study, significant differences in strength and hypertrophy occurred in upper-body measurement sites. Previous research has indicated that lower-body muscle may be more resistant to exercise-induced damage (8) and is slower to manifest observable morphological adaptations $(1,73)$. The authors suggest a longer experimental training period may be necessary to properly compare high-intensity, low-volume and moderateintensity, high volume training protocols in regards to lower-body skeletal muscle hypertrophy (35).

\section{Gaps in the Literature}

Thus far, RT research has concluded that exercise volume is an important mediator of skeletal muscle hypertrophy. Mixed results have been reached across the many studies assessing changes in muscle size using different relative intensity training protocols in well-trained men. Even further, the inclusion of exercise regimens that allow for the build-up of localized metabolic stress without the use of blood-flow restriction show mixed results as to metabolic stress's effects on skeletal muscle hypertrophy. Overall, the number of studies are few that assess muscular adaptations in well-trained men. 


\section{REFERENCES}

1. Abe TD, DeHoyos DV, Pollock ML, and Garzarella L. Time course for strength and muscle thickness changes following upper and lower body resistance training in men and women. Eur J Appl Physiol 81: 174-180, 2000.

2. Alway SE, MacDougal JD, Sale DG, Sutton JR, and McComas AJ. Functional and structural adaptations in skeletal muscle of trained athletes. J Appl Physiol (1985) 64: 1114-1120, 1988.

3. American College of Sports Medicine. American College of Sports Medicine position stand. Progression models in resistance training for healthy adults. Med Sci Sports Exerc 41(3): 687-708, 2009.

4. Baker D, Wilson G, and Carlyon R. Periodization: the effect on strength of manipulating volume and intensity. J Strength Cond Res 8: 235-242, 1994.

5. Brandenburg JE, and Docherty D. The effects of accentuated eccentric loading on strength, muscle hypertrophy, and neural adaptations in trained individuals. $J$ Strength Cond Res 16: 25-32, 2002.

6. Burd NA, West DW, Staples AW, Atherton PJ, Baker JM, Moore DR, Holwerda AM, Parise G, Rennie MJ, Baker SK, and Phillips SM. Low-load high volume resistance exercise stimulates muscle protein synthesis more than high-load low volume resistance exercise in young men. PLoS One 5(8): e12033, 2010.

7. Campos GER, Luecke TJ, Wendeln HK, Toma K, Hagerman FC, Murray TF, Ragg KE, Ratamess NA, Kraemer WJ, and Staron RS. Muscular adaptations in response to three different resistance-training regimens: specificity of repetition maximum training zones. Eur J Appl Physiol 88(1-2): 50-60, 2002.

8. Chen TC, Lin KY, Chen HL, Lin MJ, and Nosaka K. Comparison in eccentric exercise-induced muscle damage among four limb muscles. Eur J Appl Physiol 111: 211-223, 2011.

9. Chestnut J, and Docherty D. The effects of 4 and 10 repetition maximum weighttraining protocols on neuromuscular adaptations in untrained men. J Strength Cond Res 13: 353-359, 1999. 
10. Choi J, Takahashi H, Itai Y, and Takamatsu K. The difference between effects of "power-up type" and "bulk-up type" strength training exercises: With special reference to muscle cross-sectional area. Jpn J Phys Fitness Sports Med 47: 119-129, 1998.

11. Coffey VG, Zhong Z, Shield A, Canny BJ, Chibalin AV, Zierath JR, and Hawley JA. Early signaling responses to divergent exercise stimuli in skeletal muscle from well-trained humans. FASEB J 20(1): 190-192, 2005.

12. Craig B, and Kang H. Growth hormone release following single versus multiple sets of back squats: Total work versus power. J Strength Cond Res 8: 270$275,1994$.

13. Ebben WP, Kindler AG, Chirdon KA, Jenkins NC, Polichnowski AJ, and Ng AV. The effects of high-load vs. high-repetition training on endurance performance. J Strength Cond Res 18(3): 513-517, 2004.

14. Enoka RM. Neuromechanical basis of kinesiology. Human Kinetics, Champaign, IL. 1988.

15. Evans WJ. Effects of exercise on senescent muscle. Clin Orthopaed Rel Res 403: S211-S220, 2002.

16. Fleck SJ, and Kraemer WJ. Resistance training: physiological responses and adaptations (part 3). Phys Sportsmed 16(5): 63-73, 1988.

17. Fry AC. The role of resistance exercise intensity on muscle fibre adaptations. Sports Med 34(10): 663-679, 2004.

18. Gabriel DA, Kamen G, and Frost G. Neural adaptations to resistive exercise: Mechanisms and recommendations for training practices. Sports Med 36: 133 $149,2006$.

19. Goldberg AL, Etlinger JD, Goldspink DF, and Jablecki C. Mechanism of workinduced hypertrophy of skeletal muscle. Med Sci Sports 7(3): 185-198, 1975.

20. Gordon SE, Kraemer WJ, Vos NH, Lynch JM, and Knuttgen HG. Effect of acidbase balance on the growth hormone response to acute high-intensity cycle exercise. J Appl Physiol 76: 821-829, 1994.

21. Goto K, Ishii N, Kizuka T, and Takamatsu K. The impact of metabolic stress on hormonal responses and muscular adaptations. Med Sci Sport Exerc 37: 955963,2005 
22. Harber MP, Fry AC, Rubin MR, Smith JC, and Weiss LW. Skeletal muscle and hormonal adaptations to circuit weight training in untrained men. Scand J Med Sci Sports 14(3): 176-185, 2004.

23. Hill M, and Goldspink G. Expression and splicing of the insulin-like growth factor gene in rodent muscle is associated with muscle satellite (stem) cell activation following local tissue damage. J Physiol 549: 409-418, 2003.

24. Holm L, Reitelseder S, Pedersen TG, Doessing S, Petersen SG, Flyvbjerg A, Andersen JL, Aagaard P, and Kjaer M. Changes in muscle size and MHC composition in response to resistance exercise with heavy and light loading intensity. J Appl Physiol (1985) 105: 1454-1461, 2008.

25. Hong A, Hong S, and Shin Y. Effects of resistance training on muscle strength, endurance, and motor unit according to ciliary neurotrophic factor polymorphism in male college students. J Sports Sci Med 13(3): 680-688, 2014.

26. Hornberger TA. Mechanotransduction and the regulation of mTORC1 signaling in skeletal muscle. Int J Biochem Cell Biol 43(9): 1267-1276, 2011.

27. Huczel HA, and Clarke DH. A Comparison of strength and muscle endurance in strength-trained and untrained women. Eur J Appl Occup Phsyiol 64: 467470, 1992.

28. Jones DA, and Rutherford OM. Human muscle strength training: The effects of three different regimens and the nature of the resultant changes. J Physiol 391: $1-11,1987$.

29. Kraemer, WJ. Endocrine responses to resistance exercise. Med Sci Sports Exerc 20(5): S152-157, 1988.

30. Kraemer W J, Fleck SJ, Dziados JE, Hayman EA, Marchitelli LJ, Gordon SE, Mello R, Frykman PN, Koziris LP, and Triplett NT. Changes in hormonal concentrations after different heavy-resistance exercise protocols in women. $J$ Appl Physiol 75: 594-604, 1993.

31. Krieger JW. Single versus multiple sets of resistance exercise: A meta-regression. J Strength Cond Res 23: 1890-1901, 2009.

32. Krieger JW. Single vs. multiple sets of resistance exercise for muscle hypertrophy: A meta-analysis. J Strength Cond Res 24: 1150-1159, 2010. 
33. Leger B, Cartoni R, Praz M, Lamon S, Deriaz O, Crettenand A, Gobelet C, Rohmer P, Konzelmann M, Luthi F, and Russell AP. Akt signaling through GSK-3beta, mTOR and Foxo1 is involved in human skeletal muscle hypertrophy and atrophy. J Physiol 576: 923-933, 2006.

34. MacDougall JD, Sale DG, Always SE, and Sutton JR. Muscle fiber number in biceps brachii in bodybuilders and control subjects. J Appl Physiol 57: 1399$1403,1984$.

35. Mangine GT, Hoffman JR, Gonzalez AM, Townsend JR, Wells AJ, Jajtner AR, Beyer KS, Boone CH, Miramonti AA, Wang R, LaMonica MB, Fukuda DH, Ratamess NA, and Stout JR. The effect of training volume and intensity on improvements in muscular strength and size in resistance-trained men. Physiol Rep 3(8): e12472, 2015.

36. Masuda K, Choi JY, Shimojo H, and Katsuta S. Maintenance of myoglobin concentration in human skeletal muscle after heavy resistance training. Eur $J$ Appl Physiol Occup Physiol 79(4): 347-352, 1999.

37. Maughan RJ, Watson JS, and Weir J. Strength and cross-sectional area of human skeletal muscle. J Physiol 338: 37-49, 1983.

38. McCall GE, Byrnes WC, Fleck SJ, Dickinson A, and Kraemer WJ. Acute and chronic hormonal responses to resistance training designed to promote muscle hypertrophy. Can J Appl Physiol 24(1): 96-107, 1999.

39. McDonagh MJ, and Davies CT. Adaptive response of mammalian skeletal muscle to exercise with high loads. Eur J Appl Physiol Occup Physiol 52(2): 139-155, 1984.

40. Mitchell CJ, Churchward-Venne TA, West DD, Burd NA, Breen L, Baker SK, and Phillips SM. Resistance exercise load does not determine trainingmediated hypertrophic gains in young men. $J$ Appl Physiol (1985) 113: 71-77, 2012 .

41. Moritani T, and deVries HA. Neural factors versus hypertrophy in the time course of muscle strength gain. Am J Phys Med 58(3): 115-130, 1979.

42. Mulligan SE, Fleck SJ, Gordon SE, and Koziris LP. Influence of resistance exercise volume on serum growth hormone and cortisol concentration in women. J Strength Cond Res 10: 256-262, 1996. 
43. Netreba AI, Popov DV, Liubaeva ET, Bravyi I, Prostova AB, Lemesheva I, and Vinogradova OL. Physiological effects of using the low intensity strength training without relaxation in single-joint and multi-joint movements. Ross Fiziol Zh Im I M Sechenova 93: 27-38, 2007.

44. Nielsen AR, and Pedersen BK. The biological roles of exercise-induced cytokines: IL-6, IL-8, and IL-15. Appl Physiol Nutr Metab 32(5): 833-839, 2007.

45. Ogasawara R, Kobayashi K, Tsutaki A, Lee K, Abe T, Fujita S, Nakazato K, and Ishii N. mTOR signaling response to resistance exercise is altered by chronic resistance training and detraining in skeletal muscle. J Appl Physiol 114(7): 934-940, 2013.

46. Ogasawara R, Loenneke JP, Thiebaud RS, and Abe T. Low-load bench press training to fatigue results in muscle hypertrophy similar to high-load bench press training. Int J Clin Med 4: 114-121, 2013.

47. Peterson MD, Rhea MR, and Alvar BA. Applications of the dose-response for muscular strength development: A review of meta-analytic efficacy and reliability for designing training prescription. J Strength Cond Res 19(4): 950958, 2005.

48. Phillips SM. Short-term training: when do repeated bouts of resistance exercise become training? Can J Appl Physiol 25: 185-193, 2000.

49. Pizza FX, Peterson JM, Baas JH, and Koh TJ. Neutrophils contribute to muscle injury and impair its resolution after lengthening contractions in mice. $J$ Physiol 562(part 3): 899-913, 2005.

50. Popov DV, Tsirkun DV, Netreba AI, Tarasova OS, Prostova AB, Larina IM, Borovik AS, and Vinogradova OL. Hormonal adaptations determines the increase in muscle mass and strength during low-intensity strength training without relaxation. Fiziol Cheloveka 32: 121-127, 2006.

51. Quinn LS. Interleukin-15: a muscle-derived cytokine regulating fat-to-lean body composition. J Anim Sci 86(14 Suppl.): E75-83, 2008.

52. Rhea MR, Ball SED, Phillips WT, and Burkett LN. A comparison of linear and daily undulating periodized programs with equated volume and intensity for strength. J Strength Cond Res 16(2): 250-255, 2002.

53. Rooney KJ, Herbert RD, and Balnave RJF. Fatigue contributes to the strength training stimulus. Med Sci Sport Exerc 26: 1160-1164, 1994. 
54. Sale DG, MacDougall JD, Alway SE, and Sutton JR. Voluntary strength and muscle characteristics in untrained men and women and male bodybuilders. $J$ Appl Physiol (1985) 62: 1786-1793, 1987.

55. Sale DG, Upton AR, McComas AJ, and MacDougall JD. Neuromuscular function in weight-trainers. Exp Neurol 82: 521-531, 1983.

56. Schoenfeld BJ. The mechanisms of muscle hypertrophy and their application to resistance training. J Strength Cond Res 24(10): 2857-2872, 2010.

57. Schoenfeld BJ. Is there a minimum intensity threshold for resistance traininginduced hypertrophic adaptations? Sports Med 43: 1279-1288, 2013.

58. Schoenfeld BJ, Peterson MD, Ogborn D, Contreras B, and Sonmez GT. Effects of low- vs. high-load resistance training on muscle strength and hypertrophy in well-trained men. J Strength Cond Res 29(10): 2954-2963, 2015a.

59. Schoenfeld BJ, Ratamess NA, Peterson MD, Contreras MD, and Sonmez GT. Influence of resistance training frequency on muscular adaptations in welltrained men. J Strength Cond Res 29(7): 1821-1829, $2015 \mathrm{~b}$.

60. Schoenfeld BJ, Ratamess NA, Peterson MD, Contreras B, Sonmez GT, and Alvar BA. Effects of different volume-equated resistance training loading strategies on muscular adaptations in well-trained men. J Strength Cond Res 28(10): 2909-18, 2014.

61. Schott J, McCully K. and Rutherford OM. The role of metabolites in strength training. II. Short versus long isometric contractions. Eur J Appl Physiol 71: 337-341, 1995.

62. Schuenke MD, Herman J, and Staron RS. Preponderance of evidence proves "big" weights optimize hypertrophic and strength adaptations. Eur J Appl Physiol 113(1): 269-271, 2013.

63. Serrano AL, Baeza-Raja B, Pediguero E, Jardí M, Muñoz-Cánoves P. Interleukin6 is an essential regulator of satellite cell-mediated skeletal muscle hypertrophy. Cell Metab 7(1): 33-44, 2008.

64. Shinohara M, Kouzaki M, Yoshihisa T, and Fukunaga T. Efficacy of tourniquet ischemia for strength training with low resistance. Eur J Appl Physiol 77: 189191, 1998. 
65. Smilios I, Pilianidis T, Karamouzis M, and Tokmakidis SP. Hormonal responses after various resistance exercise protocols. Med Sci Sport Exerc 35: 644-654, 2003.

66. Smith RC, and Rutherford OM. The role of metabolites in strength training. I. A comparison of eccentric and concentric contractions. Eur J Appl Physiol 71: 332-336, 1995.

67. Staron RS, Karapondo DL, Kraemer WJ, Fry AC, Gordon SE, Falkel JE, Hagerman FC, and Hikida RS. Skeletal muscle adaptations during early phase of heavy-resistance training in men and women. $J$ Appl Physiol 76(3): 1247$55,1994$.

68. Stone MH, Potteiger JA, Pierce KC, Proulx CM, O'Bryant HS, Johnson RL, and Stone ME. Comparison of the effects of three different weight-training programs on the one repetition maximum squat. J Strength Cond Res 14:332337,2000 .

69. Suga T, Okita K, Morita N, Yokota T, Hirahayashi K, Horiuchi M, Takada S, Takahashi T, Omokawa M, Kinugawa S, and Tsutsui H. Intramuscular metabolism during low-intensity resistance exercise with blood flow restriction. J Appl Physiol 106: 1119-1124, 2009.

70. Takarada Y, Nakamura Y, Aruga S, Onda T, Miyazaki S, and Ishii N. Rapid increase in plasma growth hormone after low-intensity resistance exercise with vascular occlusion. J Appl Physiol 88: 61-65, 2000.

71. Tanimoto M, and Ishii N. Effects of low-intensity resistance exercise with slow movement and tonic force generation on muscular function in young men. $J$ Appl Physiol (1985) 100: 1150-1157, 2006.

72. Tanimoto M, Sanada K, Yamammoto K, Kawano H, Gando Y, Tabaata I, Ishii N, and Miyachi M. Effects of whole-body low-intensity resistance training with slow movement and tonic force generation on muscular size and strength in young men. J Strength Cond Res 22: 1926-1938, 2008.

73. Tesch PA. Skeletal muscle adaptations consequent to long-term heavy resistance exercise. Med Sci Sport Exerc 20(5): S132-S134, 1988.

74. Tesch PA, Colliander EB, and Kaiser P. Muscle metabolism during intense, heavy-resistance exercise. Eur J Appl Physiol Occup Physiol 55: 362-366, 1986. 
75. Tesch PA, and Larsson L. Muscle hypertrophy in bodybuilders. Eur J Appl Physiol Occup Physiol 49: 301-306, 1982.

76. Toigo $\mathrm{M}$ and Boutellier U. New fundamental resistance exercise determinants of molecular and cellular muscle adaptations. Eur J Appl Physiol 97: 643-663, 2006.

77. Vandenburgh HH. Motion into mass: How does tension stimulate muscle growth? Med Sci Sport Exerc 19(5): S142-S149, 1987.

78. Vierck J, O’Reilly B, Hossner K, Antonio J, Byrne K, Bucci L, and Dodson M. Satellite cell regulation following myotrauma caused by resistance exercise. Cell Biol Int 24(5): 263-272, 2000.

79. Wernbom M, Jarrebring R, Andreasson MA, and Augustsson J. Acute effects of blood flow restriction on muscle activity and endurance during fatiguing dynamic knee extensions at low load. $J$ Strength Cond Res 23(8): 2389-2395, 2009.

80. Willoughby DS. A comparison of three selected weight training programs on the upper and lower body strength of trained males. Ann J Appl Res Coach Athl Mar: 124-146, 1992.

81. Wilmore JH, Costill DL, and Kenney LW. Physiology of sport and exercise. 4th ed. Human Kinetics, Champaign, IL. 2007.

82. Wolfe BL, LeMura LM, and Cole PJ. Quantitative analysis of single- vs. multiple-set programs in resistance training. $J$ Strength Cond Res 18: 35-47, 2004.

83. Zatsiorsky VM. Science and Practice of Strength Training. Champaign, IL: Human Kinetics, 1995. 